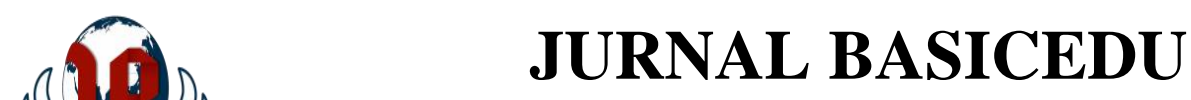

Volume 5 Nomor 3 Tahun 2021 Halaman 1271-1276

Research \& Learning in Elementary Education https://jbasic.org/index.php/basicedu

\title{
Efektivitas Penggunaan Media Film Animasi Terhadap Peningkatan Keterampilan Menulis Cerita
}

\author{
Khavisa Pranata $^{1 凶}$, Yauma Widya kartika ${ }^{2}$, Zulherman $^{3}$ \\ Pendidikan Guru Sekolah Dasar, Universitas Muhammadiyah Prof.DR.HAMKA, Indonesia ${ }^{1,2,3}$ \\ E-mail: khavisapranata@uhamka.ac.id ${ }^{1}$, yaumawika15@ gmail.com $^{2}, \underline{\text { zulherman@ @uhamka.ac.id }}^{3}$
}

\begin{abstract}
Abstrak
Pada pembelajaran digital di sekolah dasar telah banyak berbagai metode teknis yang digunakan seperti dalam upaya meningkatkan motivasi,minat dan pemahaman siswa dalam menerima materi, namun belum ke dalam aspek peningktan keterampilan menulis. Penelitian ini bermaksud untuk membuktikan efektivitas penggunaan media film animasi terhadap peningkatan keterampilan menulis cerita untuk siswa kelas IV SDN Rambutan 01 Jakarta Timur pada tahun ajaran 2019/2020. Metode yang digunakan dalam penelitian ini adalah metode quasi eksperimen dengan subjek dibagi menjadi dua kelas yaitu kelas kontrol dan kelas eksperimen. Pengambilan sampel dilakukan dengan teknik sampel jenuh dengan populasi kelas A dan B berjumlah 60 orang siswa. Instrumen penelitian berupa tes menulis cerita. Validasi dalam penelitian ini menggunakan Expert Judgement. Uji persyaratan analisis yang digunakan yaitu uji Liliefors untuk normalitas dan uji Fisher untuk homogenitas. Data menunjukan bahwa data terdistribusi normal dan data juga bersifat homogen, sedangkan untuk uji hipotesis data menujukan penggunaan media film animasi efektif, sehingga disimpulkan terbukti ada peningkatan keterampilan menulis pada siswa sekolah dasar.
\end{abstract}

Kata Kunci: Media Pembelajaran, Film Animasi, Keterampilan menulis.

\section{Abstract}

This study aims to determine the effectiveness of using animated film media to increase the writing skills of fourth grade students of SDN 01 Rambutan, East Jakarta in the academic year 2019/2020. The method used in this research is a quasi-experimental method with the subject divided into two classes, namely the control class and the experimental class. Sampling was done by saturated sampling technique with a population of class A and B totaling 60 students. The research instrument was a story writing test. Validation in this study using Expert Judgment. The analysis requirements test used in this study were the liliefors test for normality and Fisher's test for homogeneity. The data shows that the data is normally distributed and the data is also homogeneous, while to test the data hypothesis the use of animated film media is effective because it is proven that there is an increase in writing skills in students.

Keywords: Learning Media; Animated Film; Writing Skills.

Copyright (c) 2021 Khavisa Pranata, Yauma Widya Kartika, Zulherman

Corresponding author :

Email : khavisapranata@uhamka.ac.id

DOI : https://doi.org/10.31004/basicedu.v5i3.867 
1272 Efektivitas Penggunaan Media Film Animasi Terhadap Peningkatan keterampilan Menulis Ceritakhavisa Pranata, Yauma Widya Kartika, Zulherman

DOI : https://doi.org/10.31004/basicedu.v5i3.867

\section{PENDAHULUAN}

Pendidikan merupakan sebauah tindakan secara sadar, sistematis untuk menciptakan suasana belajarmengajar agar siswa mampu mengembangkan potensi diri. Dengan pendidikan maka dapat membangun suatu peradaban yang semakin hari semakin berkembang. Salah satu hal terpenting dalam pendidikan adalah Bahasa. Bahasa merupakan sarana pengantar pendidikan di mana dengan memahami bahasa yang digunakan sebagai pengantar pendidikan dapat membantu memahami apa yang sedang dipelajari sehingga ilmunya dapat tersampaikan dan diterima dengan baik (Meilana et al., 2021). Dalam berbahasa ada empat keterampilan yaitu keterampilan menyimak,berbicara dan membaca serta keterampilan menulis (Zulfadewina et al., 2020). Melalui empat keterampilan ini kita dapat menyerap dan menghantarkan pembelajaran dengan baik.

Keterampilan menulis merupakan keterampilan yang bersifat aktif-produktif, artinya keterampilan ini berfungsi agar siswa dapat menuliskan karangan, yang dari karangan tersebut akan menghasilkan sebuah karya (Kesuma et al., 2019). Keterampilan menulis yang paling rumit dan kompleks, akan tetapi keterampilan ini sangatlah penting keberadaannya pada setiap pembelajaran yang dialami siswa selama menuntut ilmu di sekolah (Lazuardi et al., 2017). Keterampilan menulis sangat dibutuhkan, namun dalam kenyataannya keterampilan menulis kurang dapat perhatian karena kurangnya kemampuan guru dalam mengajarkan sistem penulisan sesuai kaidah seperti guru hanya membebaskan siswa untuk menulis sesuai keinginan mereka. Sedangkan kemampuan menulis seseorang dapat diperoleh dari terbiasanya seseorang menulis.

Hasil temuan di sekolah bahwa keterampilan menulis siswa di sekolah dasar kurang diasah dengan baik. Guru sering kali hanya memberikan tugas mengarang dengan sedikit penjelasan mengenai kaidah sebuah tulisan yang baik dan benar, akibatnya kreatifitas dan imajinasi peserta didik terbatas. Kurang variatifnya media yang digunakan guru juga menentukan dalam berjalannya proses belajar peserta didik karena dengan media yang variatif dapat memancing kreatifitas dan imajinasi peserta didik, maka pentingnya penelitian ini agar penggunaan media pembelajaran berkontribusi untuk membuat cara berpikir siswa sistematis dan mengetahui apa saja komponen penting dalam menulis dengan cara yang menyenangkan dan dapat dilihat langsung oleh siswa, media pembelajaran yang menarik sangat diperlukan oleh seorang guru dalam kegiatan belajar mengajar khususnya pada pembelajaran menulis cerita.

Kegiatan menulis cerita, merupakan tantangan bagi seorang guru menerapkan strategi pembelajaran agar kondisi proses kegiatan pembelajaran lebih mengutamakan kemampuan berpikir (Zulherman et al., 2020, 2021). Penyajian yang kurang menarik dapat menghambat cara berpikir siswa dan membuat siswa bosan bahkan malas untuk membuat sebuah karangan cerita (Lestari et al., 2017). Maka perlu ada strategi dan media pembelajaran yang menarik bagi siswa dan mengajak siswa berimajinasi langsung dalam cerita tersebut.

Dalam Penelitian sebelumnya oleh (Rofikhatul Ula \& Nugraha, 2020) bahwa keterampilan berbicara siswa ketika menggunakan media animasi lebih baik dari pembelajaran konvensional. Dalam penelitian lainnya oleh (Sukmanasa et al., 2017) bahwa pemebelajaran menggunakan komik digital mampu menarik minat belajar siswa, karena konten dan tampilan nya mampu memotivasi belajar siswa. Sedangkan dalam penelitian oleh (Novita \& Novianty, 2020) dimana dalam kajiannya bahwa penggunan pembelajaran audio visual animasi sangat berdampak positif terhadap hasil belajar siswa (Aslam et al., 2020). Dengan demikian penggunan media film animasi akan di ujicoba seberapa efektif terhadap peningkatan keterampilan menulis cerita untuk siswa sekolah dasar.

Penelitian ini menggunakan salah satu media yang dapat digunakan untuk meningkatkan kreatifitas dan daya khayal siswa dalam menulis yaitu media film animasi (Djannah et al., 2021; Pratiwi et al., 2021; Rahayu et al., 2021; Rostyawati et al., 2021). Film animasi dipilih karena anak sudah terbiasa dengan video-video dibandingkan dengan buku cerita. Penggunaan media film animasi di samping dapat menjadi pusat perhatian siswa, juga dapat menjadi nilai tambah karena siswa dapat dengan mudah menikmati sebuah kisah atau cerita 
1273 Efektivitas Penggunaan Media Film Animasi Terhadap Peningkatan keterampilan Menulis Ceritakhavisa Pranata, Yauma Widya Kartika, Zulherman

DOI : https://doi.org/10.31004/basicedu.v5i3.867

dalam bentuk audio visual,sehingga penelitian ini akan diuji efektifkah penggunaan media film animasi terhadap peningkatan keterampilan menulis cerita bagi siswa sekolah dasar.

\section{METODE PENELITIAN}

Penelitian dilaksanakan di SDN Rambutan 01 Jakarta Timur. populasinya yaitu seluruh siswa kelas IV SDN Rambutan 01. Populasi dalam penelitian ini adalah seluruh siswa kelas IV yang berjumlah 60 orang siswa. Sampel penelitian diambil terdiri dua kelas yaitu satu kelas eksperimen dan satu kelas kontrol. Penelitian ini menggunakan metode kuantitatif dalam bentuk kuasi eksperimen (Quasi Experimental Design). Dalam penelitian, peran media pembelajaran yang digunakan berupa media film animasi yang disesuaikan dengan keperluan kegiatan, dimana membahas mengenai materi pada tema 8 Daerah Tempat Tinggalku subtema 1 Lingkungan Tempat Tinggalku pembelajaran 1 mengenai menuliskan cerita kelas IV. Data yang dikumpulkan yaitu data utama berupa hasil tes menulis cerita siswa. Teknik analisis data digunakan untuk pengujian persyaratan analisis yaitu uji Liliefors untuk uji normalitas, dan uji Fisher untuk uji homogenitas. Sedangkan untuk uji hipotesis penelitian ini menggunakan uji-t.

\section{HASIL DAN PEMBAHASAN}

Penelitian ini menggunakan dua kelas pada kelas IV yaitu kelas A dan B. Kelas A sebagai kelas eksperimen dan kelas B sebagai kelas kontrol. jumlah siswa pada kelas A dan B adalah 30 orang per kelas. Peneliti melakukan penelitian sebanyak 1 kali pertemuan. Pada saat pembelajaran, kelas ekperimen diberikan perlakuan berupa menonton film animasi yang berjudul Sangkuriang. Pembelajaran dilakukan dalam jaringan atau daring melalui aplikasi WhatsApp dan pemberian tugas melalui Google Form. Tugas yang diberikan berupa soal essay yaitu menuliskan cerita rakyat daerah yang berjudul Sangkuriang. Untuk kelas kontrol diberikan tugas yang sama namun tidak diberikan perlakuan yaitu menonton film animasi.

Peneliti memberikan posttest berupa 1 soal essay melalui Google Form yang diisi oleh 60 siswa. Halaman Google Form yang diberikan kepada kelas kontrol dan kelas eksperimen berbeda karena peneliti memasukan link film animasi pada halaman Google Form kelas eksperimen sedangkan pada kelas kontrol hanya diberikan soal saja. Dari posttest tersebut diperoleh nilai rata-rata pada kelas eksperimen adalah 78,6 dan pada kelas kontrol adalah 74,7. Dari data tersebut dapat disimpulkan bahwa nilai rata-rata kelas eksperimen lebih tinggi daripada nilai rata-rata kelas kontrol.

Dalam kegiatan pembelajaran terjadi perbedaan dari kelas yang diberikan perlakuan berupa menonton film animasi dan yang tidak. Hal ini dibuktikan dengan nilai rata-rata masing-masing kelas di mana nilai ratarata kelas eksperimen lebih tinggi dibandingkan dengan kelas kontrol.

Pada kelas kontrol, nilai tertinggi kelas kontrol yaitu 83 dan nilai terendah 64, dengan nilai mean 74,7, median 75,87 , modus 74,7, varians 28,8 , dan simpangan baku 5,36. 


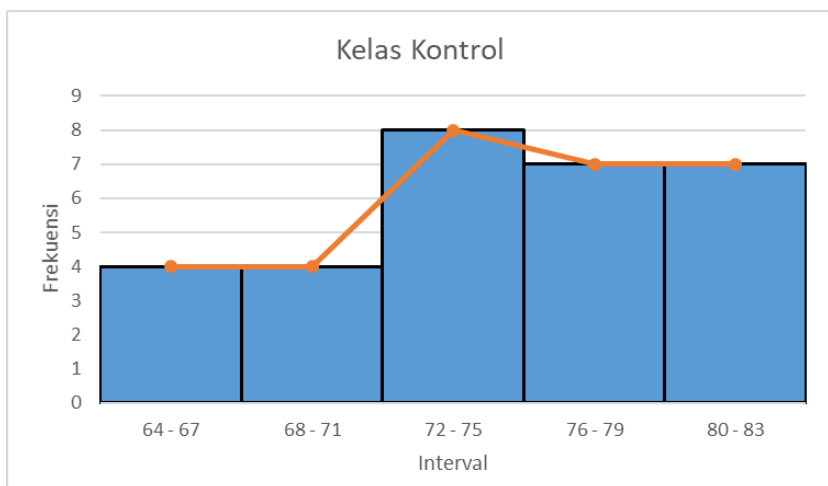

Grafik 1 Grafik Histogram dan Poligon Nilai Keterampilan Menulis Cerita Kelas Kontrol

Pada kelas eksperimen, didapatkan nilai tertinggi kelas kontrol yaitu 90 dan nilai terendah 68, dengan nilai mean 78,6, median 78,33, modus 79,15, varians 39,54, dan simpangan baku 6,28.

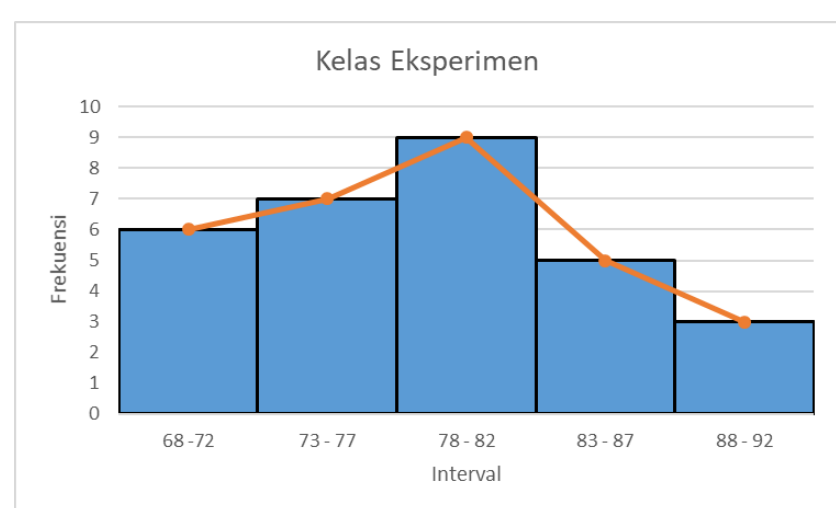

\section{Grafik 2 Grafik Histogram dan Poligon Nilai Keterampilan Menulis Cerita Kelas Eksperimen}

Hasil perhitungan pada kelas kontrol dengan proses pembelajaran tanpa menggunakan media film animasi sebelum menulis cerita serta kelas eksperimen dengan proses pembelajaran dengan menggunakan media film animasi di atas menunjukan $L_{\text {ohitung }}$ sebesar 0,161206188 dan 0,098163442 lebih kecil dari $L_{\text {otabel }}$ pada taraf signifikansi $(\alpha=0,05)$ untuk $\mathrm{n}=30$ sebesar 0,16116179 . Maka dapat disimpulkan bahwa kelas berdistribusi normal.

Hasil perhitungan uji homogenitas variansi menggunakan uji fisher diperoleh hasil yaitu varians kelas kontrol sebesar 28,85 dan varians kelas eksperimen sebesar 39,54. Kemudian $F_{\text {hitung }}$ dihitung dengan cara varians tersebar dibagi varians terkecil, maka diperoleh $F_{\text {hitung }}$ sebesar 1,37 . Karena $F_{\text {hitung }}$ lebih kecil disbanding $F_{\text {tabel }}$ yaitu 1,85 dengan dk penyebut dan pembilang masing-masing adalah 29 atau $1,37<1,85$, maka varians kedua kelas tersebut adalah homogen.

Berdasarkan pengujian uji hipotesis dengan uji-t dalam penelitian yang dilakukan oleh peneliti di SDN Rambutan 01dengan kriteria jika $t_{\text {hitung }}>t_{\text {tabel }}$ maka $\mathrm{H}_{0}$ ditolak. Dari hasil perhitungan antara kelas eksperimen dan kelas kontrol diperoleh $\mathrm{t}_{\text {hitung }}=2,68$ sedangkan $\mathrm{t}_{\text {tabel }}$ pada $\alpha=0,05$ dengan $\mathrm{dk}=30$ seharga 2,042 . Karena $\mathrm{t}_{\text {hitung }}>\mathrm{t}_{\text {tabel }}$ yaitu 2,68>2,04, maka dapat disimpulkan bahwa $\mathrm{H}_{0}$ ditolak yang artinya Media Film Animasi efektif terhadap peningkatan keterampilan menulis cerita pada siswa kelas IV di SDN Rambutan 01.

Hasil dari penelitian yang telah dilakukan selaras dengan beberapa artikel yaitu dalam penelitian yang dilakukan oleh Astuti dan Mustadi dalam penelitian "pengaruh penggunaan media film animasi terhadap keterampilan menulis karangan narasi siswa kelas V SD" menunjukan adanya perbedaan pengaruh dimana media film animasi lebih berpengaruh dibandingkan dengan media gambar berseri (Astuti,. Yanuarita, Widi. Mustadi, 2014), sehingga siswa lebih baik dalam penerimaan materi pelajaran. Hubungan dalam penelitian ini 
1275 Efektivitas Penggunaan Media Film Animasi Terhadap Peningkatan keterampilan Menulis Ceritakhavisa Pranata, Yauma Widya Kartika, Zulherman

DOI : https://doi.org/10.31004/basicedu.v5i3.867

bahwa peran media animasi sangat efektif meningkat keterampilan menulis siswa. Kemudian dalam penelitian yang dilakukan oleh Anjasari "pengaruh media film animasi terhadap kemampuan menulis teks cerita fable peserta didik kelas VII MTS" menunjukkan perbedaan yang signifikan pada kegiatan kegiatan pembelajaran menulis teks cerita fabel yang tanpa menggunakan media yaitu media film animasi (Anjarsari \& Suyatno, 2018). Sehingga dalam menggunakan media animasi dapat menghasilkan sebuah prestasi dalam kemahiran menulis cerita. Selanjutnya Syahruni dkk mengemukakan dalam penelitiannya yang berjudul "Pengaruh media animasi terhadap keterampilan menulis cerota murid kelas V SD se-kota Makasaar" bahwa media sangat bermanfaat pada proses pembelajaran (Hambali et al., 2020), dalam penelitian lainnya oleh santhi bahwa media juga memberikan dampak terhadap keterampilan menulis siswa (Pertiwi, 2020). Namun dalam pengaruh yang baik ini juga masih ada keterbatasan terutama pada kemampuan menyimak, mengamati pada siswa, sehingga guru harus banyak bersabar dalam mengajarkan,sehingga akan tercapai hasil yang baik.

\section{KESIMPULAN}

Penelitian ini membuktikan bahwa media pembelajaran film animasi berpengaruh efektif terhadap peningkatan keterampilan menulis cerita siswa kelas IV SDN Rambutan 01, sehingga berdampak pada kualitas kemampuan menulis siswa semakin baik.

\section{UCAPAN TERIMAKASIH}

Terimakasih kepada Ka.Prodi PGSD FKIP UHAMKA dan pihak sekolah dasar negeri yang telah membantu seta mendukung dalam penelitian. Terima kasih juga kepada editor dan reviewer atas kesempatan yang diberikan.

\section{DAFTAR PUSTAKA}

Anjarsari, P. A., \& Suyatno, S. (2018). Pengaruh Media Film Animasi terhadap Kemampuan Menulis Teks Cerita Fabel Peserta Didik Kelas VII Mts. Sunan Giri Gresik Tahun Pembelajaran 2017/2018. Bapala, 5(2). $\quad$ https://www.neliti.com/id/publications/244491/pengaruh-media-film-animasi-terhadapkemampuan-menulis-teks-cerita-fabel-peserta

Aslam, Wahab, A. A., Syae Purrohman, P., Zulherman, \& Ampry, E. S. (2020). Internet User Behavior and Social Media in Learning. Proceedings of the 4th International Conference on Research of Educational Administration and Management (ICREAM 2020), 526(Icream 2020), 50-55.

Astuti,. Yanuarita, Widi. Mustadi, A. (2014). Pengaruh Penggunaan Media Film Animasi Terhadap Keterampilan Menulis Narasi. Jurnal Prima Edukasia, 2(2), 250-262.

Djannah, M., Zulherman, Z., \& Nurafni. (2021). Kahoot Application for Elementary School Students: Implementations of Learning Process from Distance during Pandemic period of COVID 19. Journal of Physics: Conference Series, 1783(1), 012121. https://doi.org/10.1088/1742-6596/1783/1/012121

Hambali, S., Akib, E., \& Aida Azis, S. (2020). Pengaruh media animasi terhadap keterampilan menulis cerota murid kelas V SD se-kota Makasaar. Syntax Literate, 05(06), 182-191. http://mpoc.org.my/malaysianpalm-oil-industry/

Kesuma, I. G. N., Simpen, I. W., \& Satyawati, M. S. (2019). PENINGKATAN KETERAMPILAN MENULIS NASKAH DRAMA BERBAHASA BALI MELALUI MEDIA PEMBELAJARAN FILM PENDEK. Jurnal Ilmu Sosial Dan Humaniora, 8(1), 52. https://doi.org/10.23887/jishundiksha.v8i1.21354

Lazuardi, F., Gani, E., \& Rasyid, Y. (2017). Pengaruh Model Problem Based Learning Berbantuan Media 
Audiovisual Terhadap Keterampilan Menulis Teks Laporan Hasil Observasi. Pendidikan Bahasa Dan Sastra Indonesia, 6(September), 143-150.

Lestari, A., Mudzanatun, \& Damayani, A. T. (2017). KEEFEKTIFAN MEDIA AUDIO VISUAL SEBAGAI KREATIVITAS GURU SEKOLAH DASAR DALAM MENUMBUHKAN KETERAMPILAN MENULIS PUISI SISWA. Scholaria: Jurnal Pendidikan Dan Kebudayaan, 7(3), 214. https://doi.org/10.24246/j.scholaria.2017.v7.i3.p214-225

Meilana, S. F., Aulia, N., Zulherman, \& Aji, G. B. (2021). Pengaruh Model Pembelajaran Think Pair Share (TPS) Terhadap Kemampuan Berpikir Kritis di Sekolah Dasar. Jurnal Basicedu, 5(1), 218-226. http://www.jbasic.org/index.php/basicedu/article/view/644/pdf_1

Novita, L., \& Novianty, A. (2020). Pengaruh Penggunaan Media Pembelajaran Audio Visual Animasi Terhadap Hasil Belajar Subtema Benda Tunggal Dan Campuran. JTIEE (Journal of Teaching in Elementary Education), 3(1), 46. https://doi.org/10.30587/jtiee.v3i1.1127

Pertiwi, S. (2020). Pengaruh Media Film Terhadap Keterampilan Menulis Narasi Pada Mata pelajaran Bahasa Indonesia Pada Siswa Kelas V SD 02 Pagi Cipayung. Jurnal Inovasi Pendidikan MH Thamrin, 4(1), 1019. https://doi.org/10.37012/jipmht.v4i1.196

Pratiwi, M. S., Zulherman, Z., \& Amirullah, G. (2021). The Use of the Powtoon Application in Learning Videos for Elementary School Students. Journal of Physics: Conference Series, 1783(1), 012115. https://doi.org/10.1088/1742-6596/1783/1/012115

Rahayu, N. D., Zulherman, Z., \& Yatri, I. (2021). Animated Video Media Based on Adobe After Effects ( AEF ) Application: An Empirical Study for Elementary School Students. Journal of Physics: Conference Series, 1783(1), 012116. https://doi.org/10.1088/1742-6596/1783/1/012116

Rofikhatul Ula, W. R., \& Nugraha, Y. A. (2020). PENGARUH MEDIA FILM ANIMASI TERHADAP KETERAMPILAN BERBICARA KELAS V SEKOLAH DASAR. Jurnal Ilmiah P2M STKIP Siliwangi P2M STKIP Siliwangi, 5(2), 1-6.

Rostyawati, R., Zulherman, Z., \& Bandarsyah, D. (2021). Analytical Effectiveness using Adobe Flash in Learning Energy Source at Primary School. Journal of Physics: Conference Series, 1783(1), 012125. https://doi.org/10.1088/1742-6596/1783/1/012125

Sukmanasa, E., Windiyani, T., \& Novita, L. (2017). Pengembangan Media Pembelajaran Komik Digital Pada Mata Pelajaran Ilmu Pengetahuan Sosial Bagi Siswa Kelas V Sekolah Dasar Di Kota Bogor. Jurnal Pendidikan Sekolah Dasar, 3(2), 171. https://doi.org/10.30870/jpsd.v3i2.2138

Zulfadewina, Sucipto, A., Iba, K., \& Zulherman. (2020). Development of Adobe Flash CS6 MultimediaBased Learning Media on Science Subjects Animal Breeding Materials. Jurnal Basicedu, 4(4), 13081314. https://jbasic.org/index.php/basicedu\%0ADevelopment

Zulherman, Amirullah, G., Purnomo, A., Aji, G. B., \& Supriansyah. (2021). Development of Android-Based Millealab Virtual Reality Media in Natural Science Learning. Jurnal Pendidikan Sains Indonesia (Indonesian Journal of Science Education), 9(1), 1-10. https://doi.org/10.24815/jpsi.v9i1.18218

Zulherman, Arifudin, R., \& Pratiwi, M. S. (2020). Pengaruh Model Pembelajaran Auditory, Intellectuality, Repetition (AIR) untuk Siswa Sekolah Dasar. Jurnal Basicedu, 4(4), 1267-1273. https://jbasic.org/index.php/basicedu 